\title{
Mapping marine habitats with high resolution sidescan sonar
}

\author{
James E. McREA Jr. ${ }^{\text {a* }}$, H. Gary GREENE ${ }^{a}$, Victoria M. O'CONNELL ${ }^{b}$, W. Waldo WAKEFIELD \\ ${ }^{a}$ Center for Habitat Studies, Moss Landing Marine Laboratories, PO Box 450, Moss Landing CA 95039, USA \\ ${ }^{\mathrm{b}}$ Alaska Department of Fish and Came, 304 I ake St., Sitka AK 99835, USA \\ ${ }^{c}$ Institute of Marine and Coastal Sciences, Rutgers University, New Brunswick NJ 08901, USA
}

Revised 29 June 1999; accepted 16 August 1999

\begin{abstract}
The application of marine geophysics and GIS techniques to the characterization of benthic habitats has increased the ability of fisheries managers to assess distribution and habitat types beyond common practices. We report upon a $150 \mathrm{kHz}$ sidescan sonar survey offshore of Kruzof Island, Alaska undertaken to characterize rockfish (Sebastes) habitat. Using GIS, MapGrafix and Map*Factory we determined the percentage of seafloor cover that exists in our survey area. Bathymetry in the study area was determined with sidescan interferometry. All XYZ data were gridded using Surfer and plotted in shaded relief, bathymetric contour, and 3-dimensional formats. Contoured bathymetry was used as an overlay in MapGrafix. Small sub-areas were extracted from the bathymetric data for closer study, and gridded in Surfer. Areas of the mosaic where backscatter patterns were not distinct were verified with hand samples and video collected with the submersible Delta. The use of submersibles for verification of interpreted lithologies and surface textures enables a high degree of accuracy for the interpretations. Lithotypes were lumped into larger groups based on morphology and fish associations with different morphologies verified using the submersible. The accuracy of digital maps from high-resolution sidescan sonar data allows a close quantification of the areal extents of these important features, directing the application of management strategies to critical areas.(C) 1999 Ifremer / CNRS / IRD / Éditions scientitiques et médicales Elsevier SAS
\end{abstract}

\section{habitat / megahabitat / mesohabitat / sidescan / mapping}

Résumé - Cartographie des habitats marins par sondage à balayage latéral de haute résolution. La gestion des pêches dispose maintenant des techniques de la géophysique marine et des systèmes d'information géographique (SIG) pour caractériser la répartition et le type des habitats benthiques. Le présent travail porte sur l'habitat des sébastes, observé par sonar à balayage latéral à $150 \mathrm{kHz}$ au large de l'île Kruzof en Alaska. Le pourcentage de la surface occupée a été déterminé par SIG, MaxGrafix et Map Factory ; la bathymétrie a été établie par interférométrie à balayage latéral. Les coordonnées XYZ ont été entrées par Surfer, le relief est représenté en ombres et isobathes, en trois dimensions. Les isobathes ont été recouvertes par Map Grafix. Certains petits secteurs ont été extraits des données bathymétriques pour une étude détaillée et cartographiés par Surfer. Des zones de la mosaïque où les schémas n'étaient pas nets ont été contrôlées sur des prélèvements et observées par vidéo à l'aide du submersible Delta. L'utilisation de submersibles pour vérifier la nature des roches et la structure des surfaces apporte une grande précision dans l'interprétation ; les différents types ont été réunis en groupes fondés sur la morphologie. Les associations de poissons de morphologies différentes ont été vérifiées par submersible. La précision des cartes digitales obtenues par sondage à balayage latéral à haute résolution permet de quantifier précisément l'extension géographique de ces caractéristiques importantes, orientant l'application des stratégies de gestion vers les secteurs critiques. (C) 1999 Ifremer / CNRS / IRD / Éditions scientifiques et médicales Elsevier SAS

\section{habitat / mégahabitat / mésohabitat / balayage / cartographie}

* Correspondence and reprints: jmcrea@mlml.calstate.edu 


\section{INTRODUCTION}

The continental shelf off Mt. Edgecumbe, southern Kruzof Island (figure 1), was surveyed in July of 1996 using a $150 \mathrm{kHz}$ AMS digital sidescan sonar by Williamson and Associates of Seattle, as part of an Alaska Department of Fish and Game project to map essential fish habitats in the Gulf of Alaska. As described by the US Congress in the Magnusson-Stevens Act of 1996 and 1997, relevant management agencies were required to establish a protocol to map all essential fish habitats, to facilitate closer and more accurate management of areas that could affect commercially valuable fisheries. Traditional management methods have relied on ocean survey charts, catch per unit effort reports, and isolated submersible transects in each management area to estimate the extent of different habitats. The traditional methods are usually limited to gross descriptions of habitats with some interpolation between disparate locations of submersible dive transects or seafloor samples.

Using modern geophysical techniques and a Geographic Information System (GIS) the areal extent of rocky megahabitat in this management area was accurately determined, and further resolved into eight different types of potentially significant mesohabitats. Each habitat type was visually identified on the sonar mosaic based on

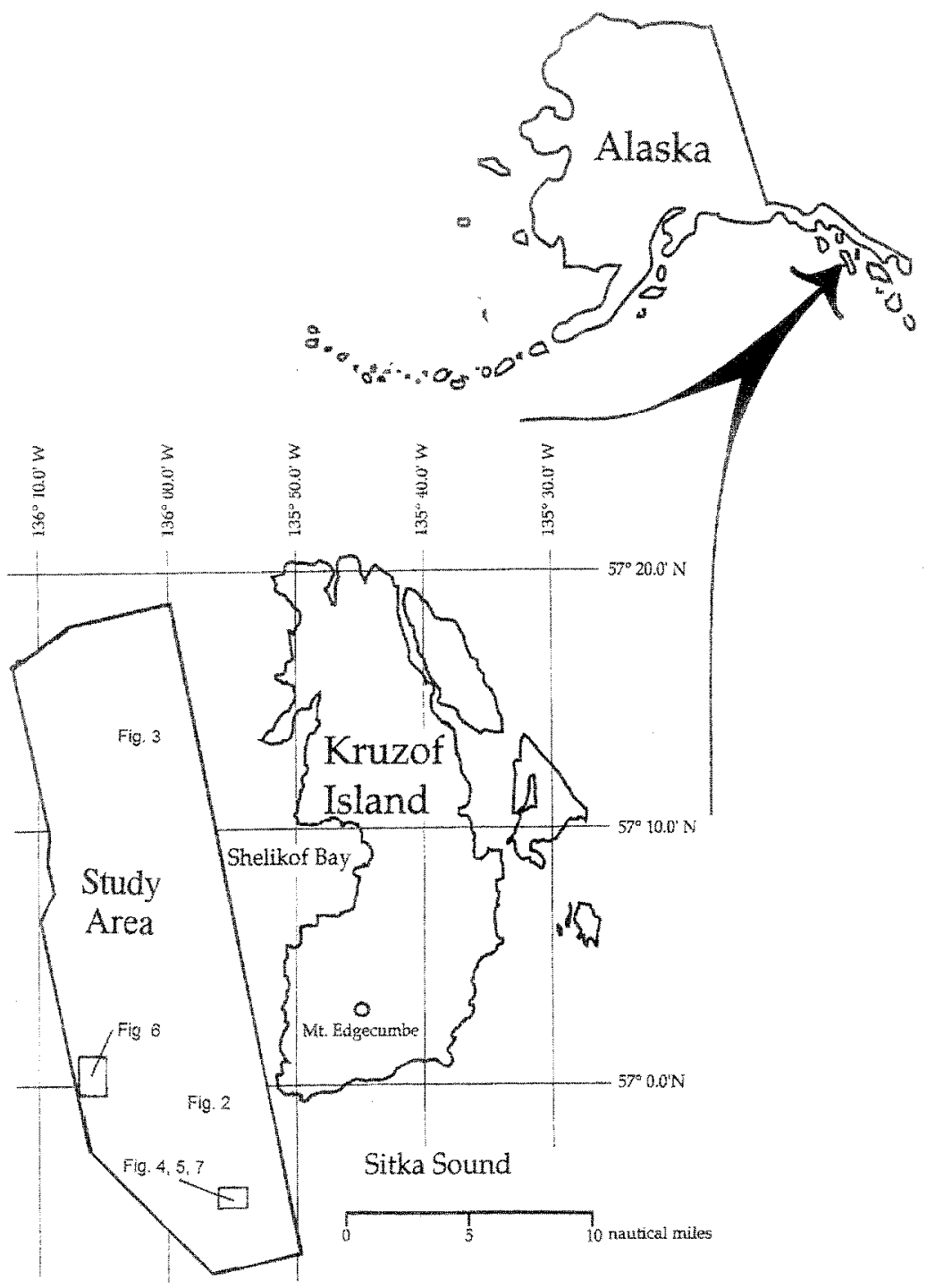

Figure 1. Index Map of Alaska, showing the study area in the Gulf of Alaska and Kruzof Island. Subsequent figure locations are indicated. 

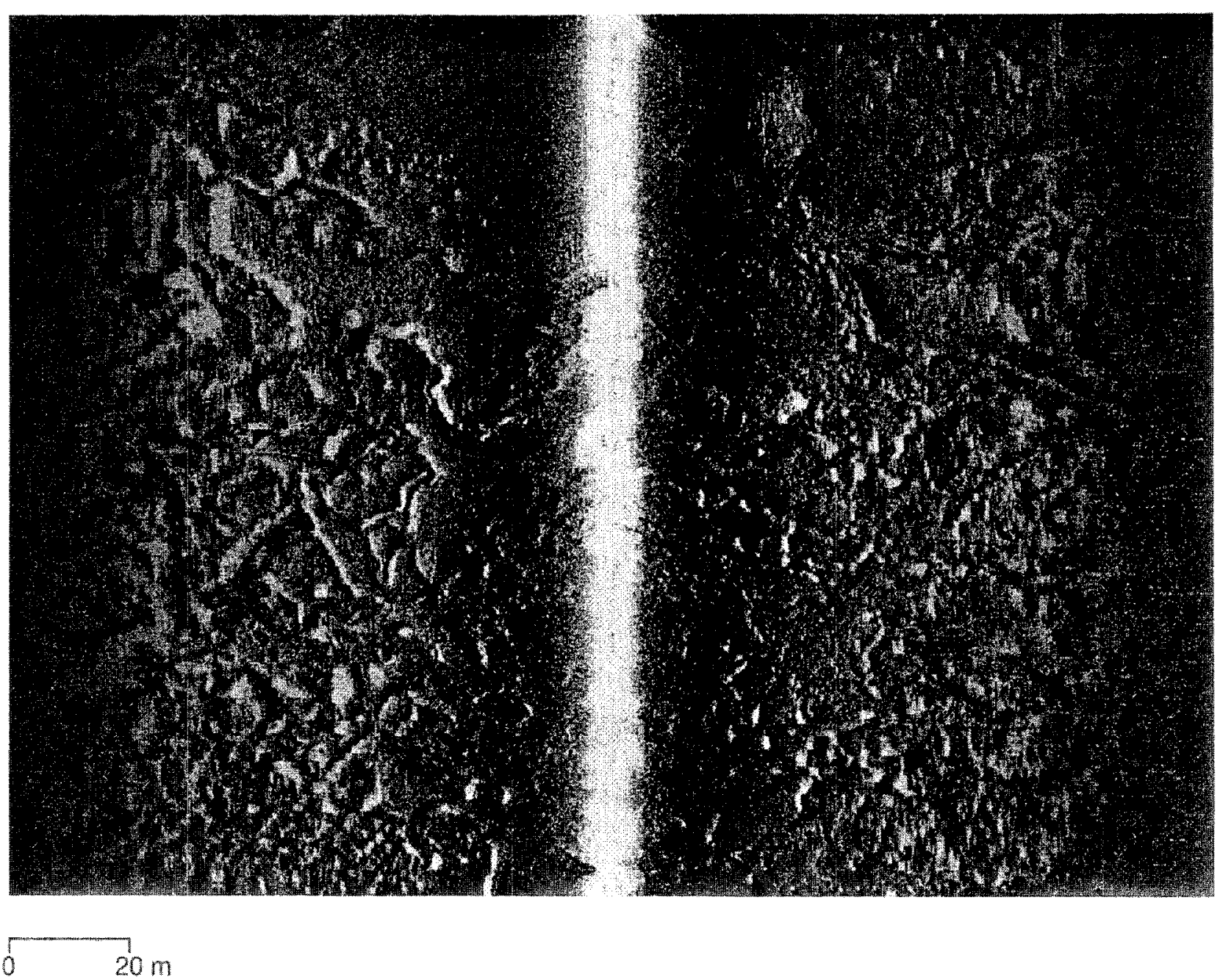

Figure 2. Digitally corrected sidescan sonar image of basalt flow from southern portion of field area. White represents acoustic shadow. Total image width $1000 \mathrm{~m}$ (500 m per channel).

unique backscatter patterns. The intensity and pattern of sonar backscatter is determined by lithology, density of the rock unit, and topographic expression. Sandy or muddy substrates with few reflectors appear grey and homogeneous, while different rocky outcrops can have very distinct patterns. The sharp compressional ridges and smooth lava ponding and collapsed supply tubes of a basalt flow from the southern portion (figure 2) are distinct and very different from the glacially-smoothed and well-weathered granitic body in the northern portion (figure 3 ) of the field area.

Visual comparison of the backscatter patterns was used to establish initial habitat areas on the sonar mosaic, in combination with cstimates of habitat potential based on surface roughness. The backscatter patterns were veri- fied with hand samples, extensive video archives, and direct observation collected from the submersible Delta. After verification, initial estimates of habitat types based solely on backscatter patterns were revised for the final maps.

The lithology of the different bottom outcrops and debris piles controls the ruggedness and morphology, which define the potential importance as a habitat or refugia for rockfish (Genus Sebastes), one of the most significant commercial fisheries in South East Alaska. Critical areas within the larger essential fish habitat such as nurseries and juvenile fish habitat areas are especially important areas for conservation efforts, and can be effectively managed and studied more closely with accurate, highly detailed maps, and a geographical information system 


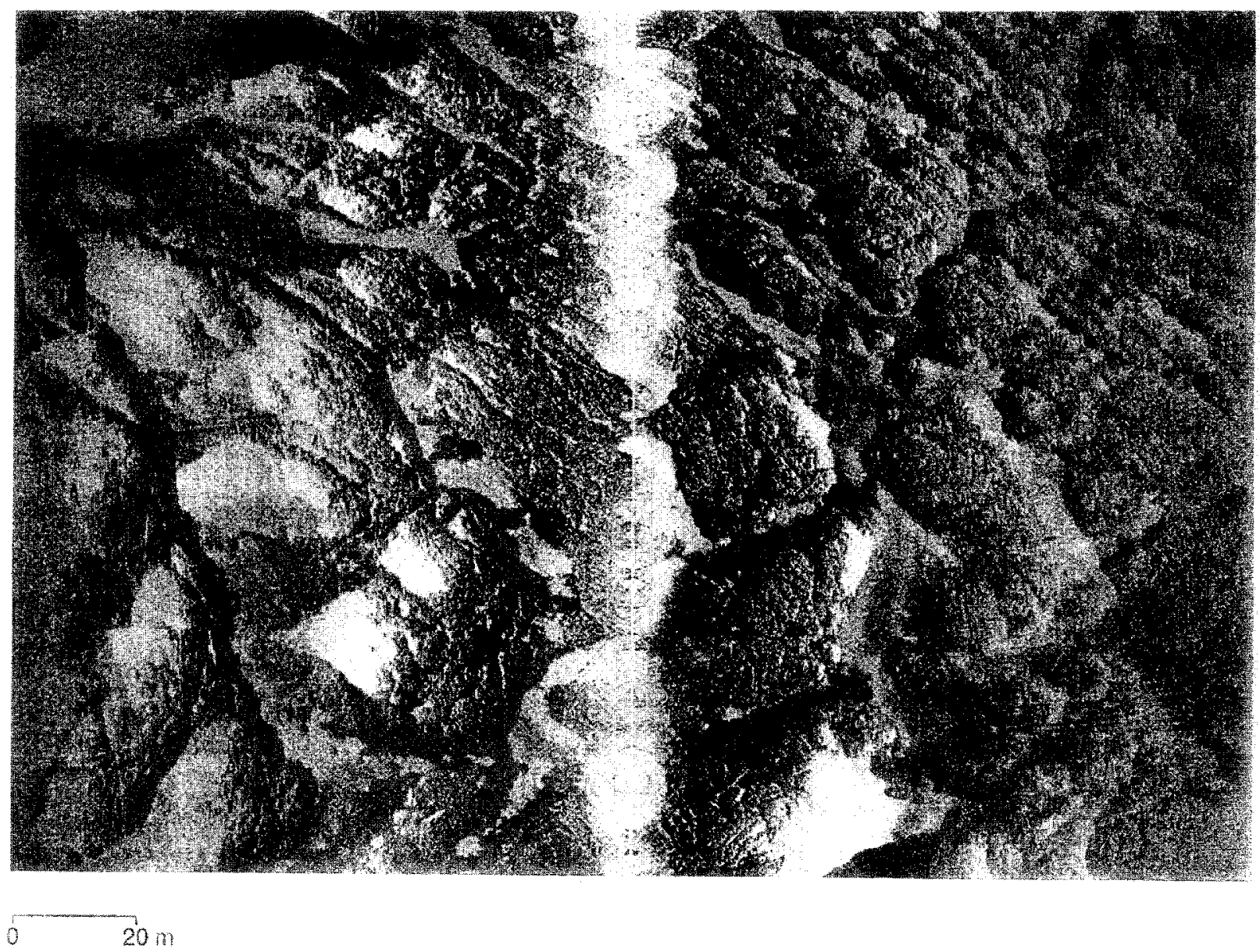

Figure 3. Digitally corrected sidescan sonar image of giacially-eroded granite from the norhern portion of fied area. White represents acoustic shadow. Total image width $1000 \mathrm{~m}$ (500 m per channel).

capable of integrating many disparate sets of data on an integrated landscape.

\section{COMPUTER METHODS OF ANALYSIS}

The results of the July 1996 survey include an interferometric swath bathymetric XYZ dataset and a sidescan sonar mosaic, and were used to interpret habitat types based on textural differences in backscatter pattern. Each type of backscatter texture and the features interpreted to produce the backscatter were traced onto a stable georeferenced mylar overlay and assigned to a habitat type unit. The interpreted habitat types were digitized using MapGrafix, a Geographical Information System (GIS) for the Macintosh, and used to prepare finished map products. The creation of a GIS for the Mt. Edgecumbe area allowed inclusion of alternate data sets including NOAA bathyme- try, regional geology, lault maps, and hisionical submersible tracklines. To make an information-rich GIS the different information was encoded into separate layers, and finished maps could be extracted from the GIS as combinations of any of the layers. For example, rocky habitats are significant for rockfish, so a map was created using only rocky outcrops and the bathymetry, and also only volcanic rocks with bathymetry. Any combination of layers could be extracted to generate maps, without changes in precision of the map or registration between different layers.

Digitization was done on a PowerPC Power Macintosh $8500 / 120$, with a large format Summagraphics Summagrid IV digitizing board. All digitizing was done in Universal Transverse Mercator, using the original scale of the sonar mosaic of 1:20000 to capture all the detail. Overlapping point files were eliminated at line intersections, and digitizing was carried out with the spaghetti method. 


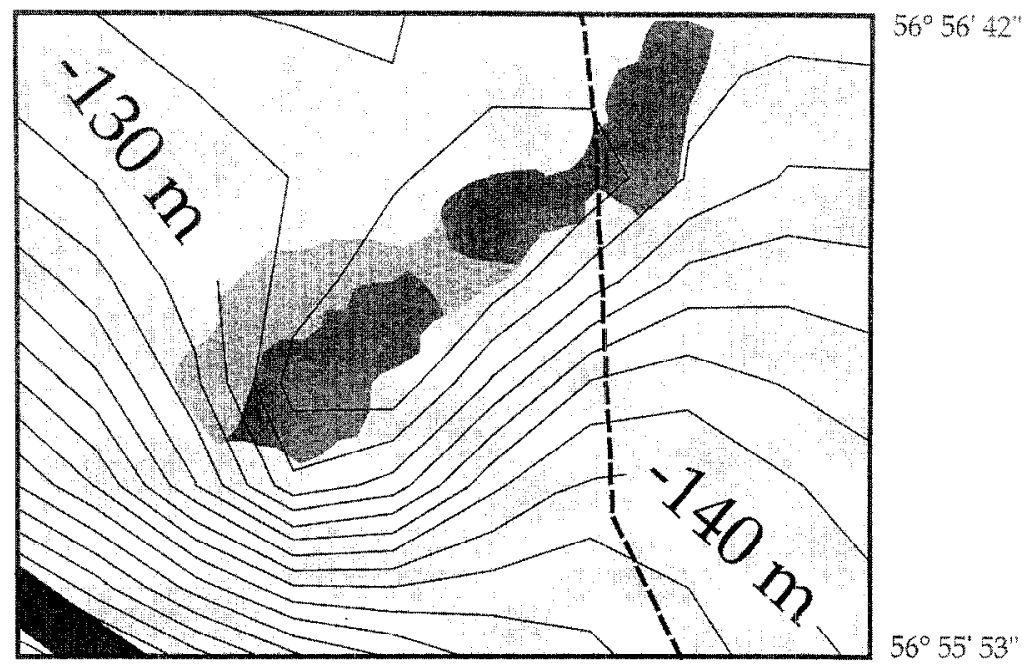

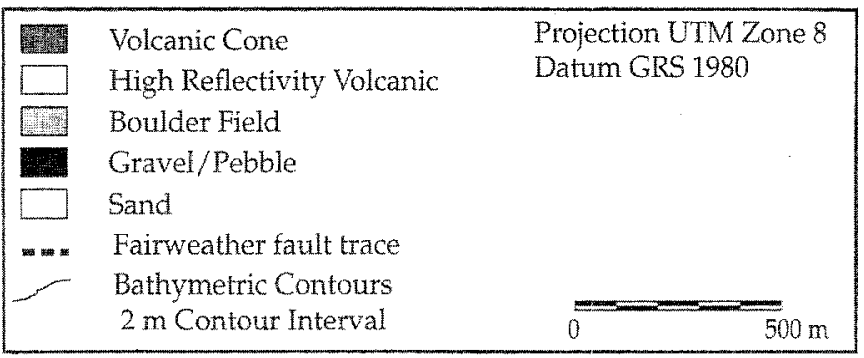

Figure 4. Map of habitats in a volcanic cone study area.

The spaghetti method is one where closed polygons are created after initial digitization of all line segments. By only digitizing each shared line segment once, registration and placement errors are eliminated because adjacent polygons share copies of identical line segments, instead of digitizing each polygon separately. The method was selected to eliminate registration errors between individual habitat unit polygons and subsequent error in assigning areal extent of each unit type. Due to the large northsouth extent of the field area (approximately $25 \mathrm{~min}$ of latitude), the map was digitized in three separate sections and assembled in the GIS together seamlessly in the final maps. Accuracy of the digitized map and control points enabled a repeatable precision of individual points that made registration of additional data sets to the interpreted map a very good fit. Other paper map products were digitized and imported as layers into the finished MapGrafix GIS. Layers included a map of regional terrestrial geology [2] the traces of the Fairweather Fault [1] and a database of all Alaska Department of Fish and Game Delta submersible dives in the area since 1989 were georefer- enced and imported into the GIS as individual layers. The bathymetric data from sidescan interferometry were also used as one of many layers imported into the final map products. Completed MapGrafix GIS maps were translated into Adobe Illustrator PostScript files using MapTrans, preserving all information about layer control, colour, and pattern. Final corrections, scales, colour and legends were completed using Adobe Illustrator on the Macintosh. Maps were imported into Map*Factory for the Macintosh, a raster based GIS program for a quick determination of the areal extent of each habitat type. Using a raster based interpretation program allowed for quick summation of the areal extent of each habitat type without requiring manual corrections for the 'island' polygon errors. An 'island' polygon is where one polygon is completely within the area of another, and the smaller overlying polygon area must be manually subtracted from the arca of the larger one to keep the total area surveyed consistent. Failure to subtract islands will make the combined total area appear numerically larger than the actual surveyed area. 


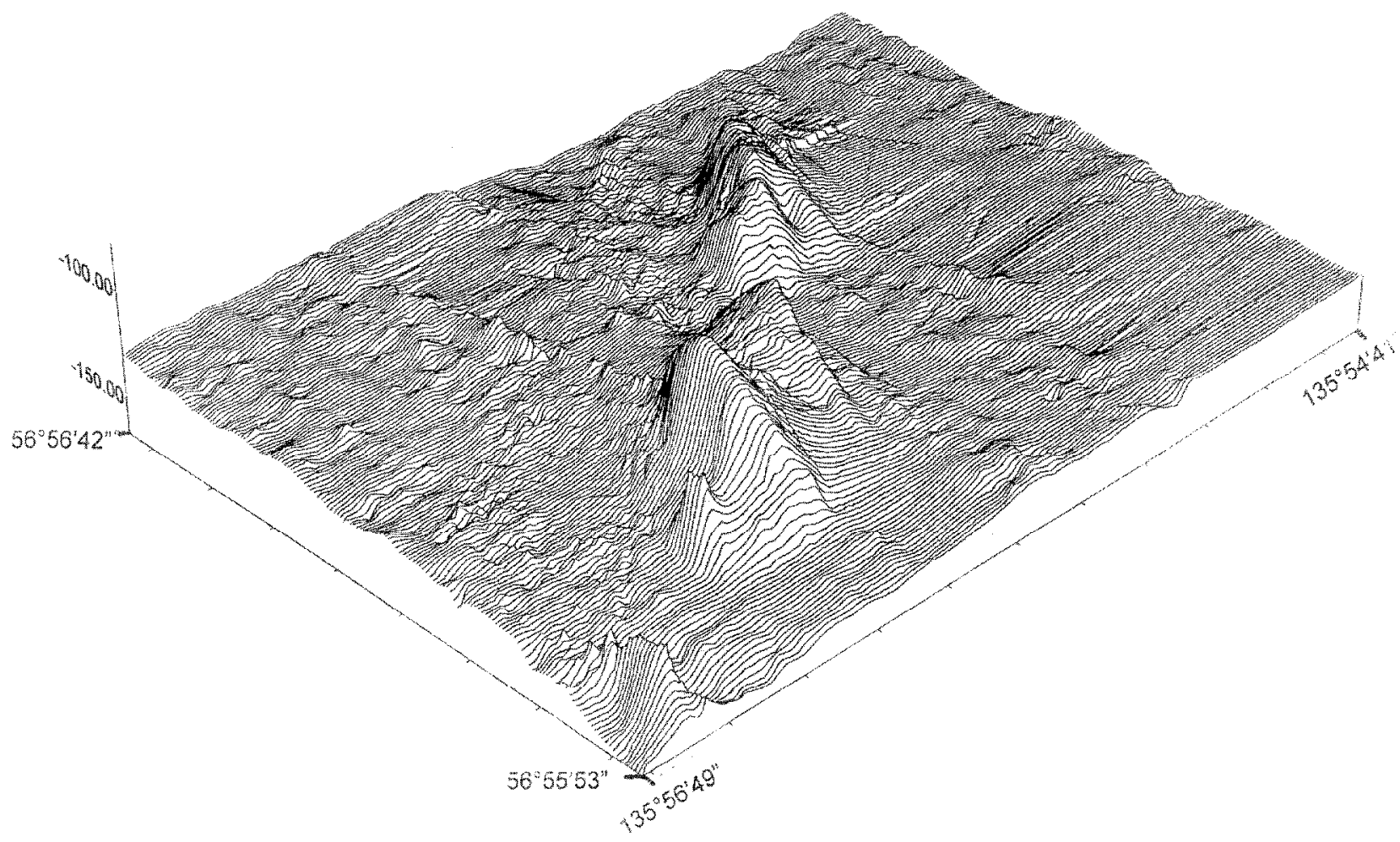

Figure 5. Digital Elevation Model (DEM) of a volcanic cone study area. $10 \mathrm{~m}$ gridded, vertical exaggeration $5 \times$.

Swath bathymetric data for the field area was collected simultaneously with proprietary acoustic interference node analysis and tracking software, developed by Williamson and Associates, and corrected for navigation with a differential geographic positioning system (dGPS). In the area of Mt. Edgecumbe the differential signal beacon allowed location to be estimated with an accuracy of $1-5 \mathrm{~m}$. The acoustic pulse of the sidescan sonar produces acoustic interference lobes at angles predicted by theoretical acoustics, with deviations from that angle caused by changes in the position of the reflector (the seafloor). Tracking information on the exact positioning of the fish and deflection from horizontal is stored as a file and used with the deviation of each of the acoustic lobes to generate a swath bathymetry analogue, accurate up to $280 \mathrm{~m}$ across track, on each $500 \mathrm{~m}$ channel. The interference lobes are more closely packed near the nadir, beam spread and decreasing interference lobe frequency reduces available data farther from nadir, limiting the maximum interference generated bathymetry to approximately two-thirds of the total channel widh. The separation of each swath along track was determined by the speed of the fish over ground. For this study the ping frequency and average speed over ground resulted in approximately $10 \mathrm{~m}$ resolution along track. All information about fish altitude, attitude, tracking, and position were digitally captured with the sidescan mosaic, and saved to magneto-optical media in real-time. Detcrminations of the scale along and across trackline were used to calculate an ellipsoid or anisotropic ratio, and used in the gridding process to ensure the gridded bathymetric results matched actual conditions of the shelf.

Using Surfer on a $486 \mathrm{PC}$ the navigation corrected $\mathrm{XYZ}$ data file was gridded using a kriging algorithm with a $100 \mathrm{~m}$ grid, the minimum grid size Surfer would support with such a large data set (over 380000 original points). With vertical exaggeration of 15 to $20 \times$ it was possible to make out gross features and center on areas of potential importance for further manipulation. Smaller areas of interest for closer study were identified in boxes 2000 to $5000 \mathrm{~m}$ on a side, were extracted from the raw ungridded data on a SUN station, and gridded with a 5 to $10 \mathrm{~m}$ grid, yielding the maximum resolution of the swath bathymetry data with much more detail. Digital elevation models with $3-5 \times$ vertical exaggeration were constructed for many detailcd study areas within the field area, for instance of the volcanic cone study area (figure 5) 


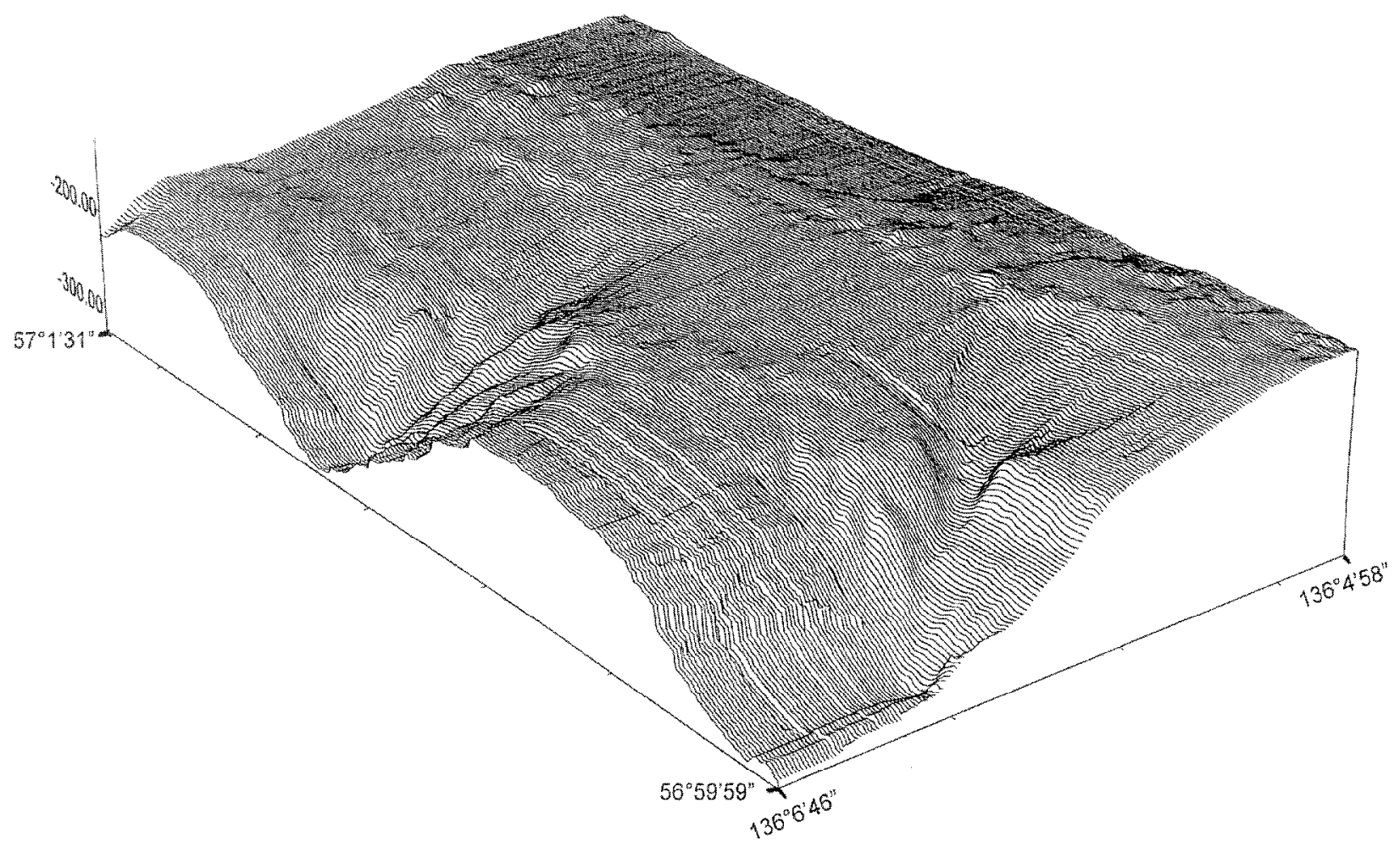

Figure 6. Digital Elevation Model (DEM) of submarine canyons in a study area. 10 meter gridded, vertical exaggeration $3 \times$.

or of the submarine canyons study area (figure 6). Sunshaded relief images were complied for each study area (figure 7).

In August 1997, the Delta submersible was used to collect seafloor rock samples from areas where the different rock types were imaged with sidescan sonar, and to verify interpretations of the sidescan sonar mosaic. Larger scale study maps were extracted for each of the proposed dive areas, to aid in reconnaissance and accurate verification of each habitat type in a dive area. A copy of a prepared dive area mosaic (e.g. figure 2) was taken with each observer in the submersible for direct comparison. A copy was also used by the person logging and directing the submersible transect from the bridge of the support vessel. The higher resolution maps were invaluable in verification and correction of interpreted habitats, and the transit of the submersible could be accurately plotted real-time with dGPS locations for later corrections to the habitat maps. When available, observers collected freshly exposed seafloor samples of the lithotypes making up each of the mesohabitats for laboralory analysis. Sample locations were accurately marked on the habitat map with dGPS location data. Dircet observation and dive video from 1997 submersible dives, and other dives in the field area over the previous 8 years were invaluable in verifying and correcting the mesohabitat types established on the final maps.

\section{RESULTS}

The complete interpreted maps were exported to MapInfo and ArcInfo/ArcView formats for the Alaska Department of Fish and Game, which uses ArcView for GIS databases. The GIS databases will be important in helping support habitat management decisions, and as a base for additional information gathered in the managed area where this study was located. New information can be placed or linked to precise locations on the habitat map or GIS. Translation was completed through TNTMips, powerful raster and vector GIS software on an X/Windows platform for Mac, PC, and Unix operating systems. Using a GIS, the Alaska Department of Fish and Game can use the maps produced in this study as a base for future work in the area. Additional data layers such as fish catch, fishing effort, management set-asides, and future submersible dives can all be added to the basemap, and smaller areas can be extracted for detailed study with great accuracy. The area mapped in this study is just one essential 


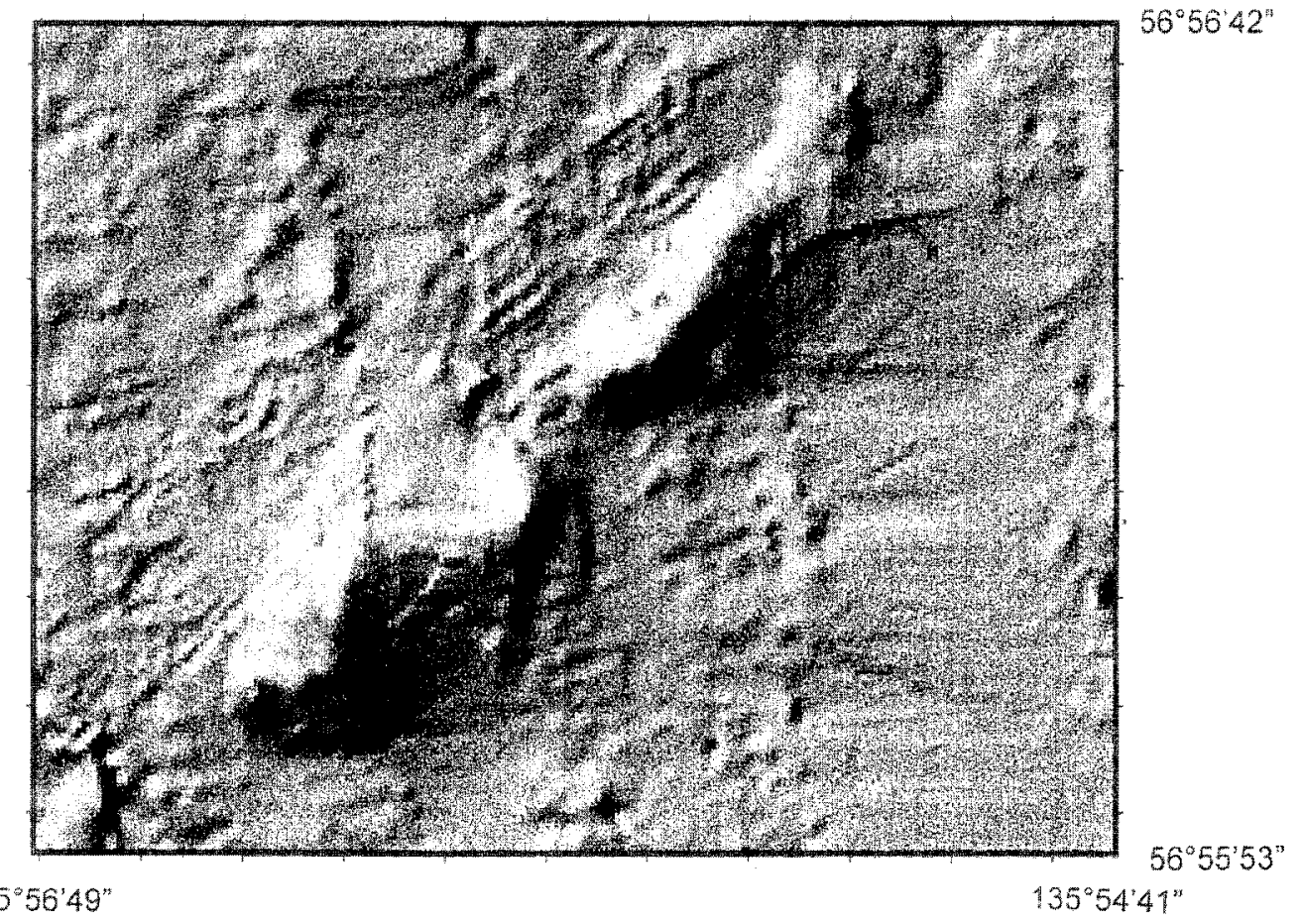

Figure 7. Sun-shaded relief image of a volcanic cone study area. $10 \mathrm{~m}$ gridded, illumination $270^{\circ}$ at $35^{\circ}$ elevation, using a central difference scale 3.0 .

habitat management area out of the many that make up the mosaic of essential fish habitat management areas in South East Alaska.

\section{CONCLUSION}

Modern computer methods of digitization and data capture provide an incredible resource for metre-scale accuracy of maps and a broad range of data that may be of crucial assistance to the effective management of a limited habitat resource. The methods presented could be applied to a diverse range of habitats, provided distinct backscatter patterns are visible on a high-resolution sidescan sonar image. Final in situ verification and sampling with the Delta submersible was invaluable in areas where differences in backscatter pattern were visually indistinct. This gave researchers a firsthand 'fish's-eye view' of the scale differences that can create a habitat area and differentiate it from other areas that appear superficially similar on sidescan sonar imaging.

\section{Acknowledgements}

Special thanks to Ray McClaine for GIS assistance, and Andrea Fildani in digitizing on the initial GIS maps, observing and reviewing submersible dive video, and George Plafker for observations from the Delta submersible. Thanks to ComGrafix for access to MapTrans and technical assistance. This study was funded by the Alaska Department of Fish and Game South East Division, through grants from the National Marine Fisheries Service Alaska Region for mapping essential fish habitats.

\section{REFERENCES}

[1] Carlson P.R., Bruns T.R., Plafker G., The Late Cenozoic offsets on the offshore connection between the Fairweather and Queen Charlotte Faults off Southeast Alaska. Mar Geol. 85 (1988) 89-97
[2] Reihle I.R., Brew D.A., Lanphere M.A., Geologic map of the Mount Edgecumbe volcanic field, Kruzof Island, Southeastem Alaska. U.S. Geological Survey Misc. Invest. Series MAP I-1983, Scale 1, 1983, 63,360. 